\title{
In Silico Homology Modeling and Epitope Prediction of Outer Membrane Protein OMP W, A Potential Vaccine Candidate against Edwardsiella tarda
}

\author{
M. Neema ${ }^{1 *}$ and I. Karunasagar ${ }^{2}$ \\ ${ }^{1}$ Division of Crop Improvement, ICAR-Central Plantation Crop Research Institute, \\ Kasaragod, Kerala-671 124, India \\ ${ }^{2}$ UNESCO MIRCEN for Marine Biotechnology, Nitte University Centre for Science Education \\ and Research, Paneer Campus, Deralakatte, Mangalore 575018, India
}

*Corresponding author

\begin{tabular}{|c|c|}
\hline & $\mathbf{D}$ \\
\hline $\begin{array}{l}\text { In Silico, Epitope, } \\
\text { Outer membrane } \\
\text { protein, } \\
\text { Edwardsiella tarda }\end{array}$ & \multirow{3}{*}{$\begin{array}{l}\text { Edwardsiella tarda is a Gram negative bacterium with a wide host range, mainly affecting } \\
\text { fishes. It is a dreaded pathogen of cat fish culture. The presence of large number of } \\
\text { serotypes of the pathogen makes the vaccine production against the pathogen a difficult } \\
\text { task. Here in this study the suitability of outer membrane protein W (OMP W) as a vaccine } \\
\text { candidate against } E \text {. tarda was investigated. OMPs has the characteristics of localization in } \\
\text { the outer membranes of Gram negative bacteria, which make them easily accessible to the } \\
\text { host antibody there by triggering an antigen antibody reaction in the host body. The 3D } \\
\text { structure of the protein was constructed using homology modeling, the quality of the } \\
\text { model was evaluated and finally the factors for a biological molecule to be considered as a } \\
\text { vaccine candidate were being checked for the OMP. The solvent accessible regions, the } \\
\text { antigenic regions, epitope positions were found out. Further the domains, patterns, motifs } \\
\text { detected together with the fact that OMP W is an adhesin strongly suggest OMP W of } E \text {. } \\
\text { tarda as a potential vaccine candidate. }\end{array}$} \\
\hline Article Info & \\
\hline & \\
\hline
\end{tabular}

\section{Introduction}

Edwardsiella tarda (E. tarda) is a Gram negative, motile, short, rod-shaped bacterium ( $1 \mu \mathrm{m}$ in diameter and $2-3 \mu \mathrm{m}$ long) belonging to the family Enterobacteriaceae. The host range of the pathogen includes human beings, fresh water and salt water fishes, snakes (Czirják et al., 2008), tortoises (Sechter et al., 1983), crocodiles (Revol, 1995), seals (Thornton et al., 1998) and frogs (Sharma et al., 1974). Edwardsiella has been implicated in gastroenteritis in humans (Spencer et al.,
2008) and in bacteremic infections that include liver abscesses (Manchanda et al., 2006) and peritonitis with sepsis (Clarridge et al., 1980). The bacterium causes edwardsiellosis / emphysematous putrefactive disease leading to mass mortality in various populations and age groups of fish. It has become one of the most serious threats to flounder farming (Kusuda and Kawai, 1998) and cat fish farming (Ye et al., 2009). Studies have shown that $E$. tarda is resistant to colicins (Stock and Wiedemann, 2001) and possess beta lactamase (Welch et al., 2009) 
activity that renders it resistant to most of the beta lactam antibiotics. Hence current research is focusing in the development of vaccine against this pathogen. In this scenario a protein which elicits antibody response in the host against the bacterium can be considered as a potential vaccine candidate. Large number of serotypes of $E$. tarda has been reported and hence developing a vaccine against E. tarda is very difficult. The outer membrane proteins are always a potent vaccine candidate against gram negative bacteria as they generate immunogenic response in the host by inducing the production of bactericidal antibodies that prevents the bacteria from establishing in the host body. In this study, using bioinformatic tools we look upon an outer membrane protein namely OMP W that could be used effectively against this pathogen. The immunogenic properties of OMP W in other gram negative bacteria like Aeromonas hydrophila (Maiti et al., 2009) and Vibrio cholerae (Nandi et al., 2005) is reported. Recent studies have also highlighted the action of OMP $\mathrm{W}$ as an oral vaccine (Dubey et al., 2016) as well as its role in transport of hydrophobic molecules (Hong et al., 2006) and also in osmoregulation (Xu et $a l$. , 2004). Hence in this study we analyze OMP $\mathrm{W}$ of the enterobacterial pathogen $E$. tarda using bioinformatics tools to establish a structure function relationship and to predict the antigenic determinants of the protein which makes it a potential vaccine candidate.

\section{Materials and Methods}

\section{Retrieval of target sequence}

The amino acid sequence of OMP W of $E$. tarda was obtained from the Swissprot sequence database UniProtKB/Swiss-prot (http://www.expasy.org/uniprot) Accession D0ZH93. This is a 214aminoacid protein. Since the structure of E. tarda OMP W was not available in the protein data bank (PDB), we looked upon constructing a 3D model of the protein.

\section{Homology modeling}

The approach of homology modeling was used in constructing a 3D model of E. tarda OMP $\mathrm{W}$. Here the protein is modeled based on the alignment between the target and template. The sequential diagram for homology modeling is illustrated in Figure 1. NCBI Protein BLAST of E. tarda OMP W (target) was done against PDB data base to obtain a structurally similar protein namely 'template'. The target - template sequence alignment was done using CLUSTAL W (www.ebi.ac.uk/ clustalw/). The resulting alignment file is provided to SWISS MODEL server (http://swissmodel.expasy.org/workspace/inde x.php?func=modelling_align1) (Arnold et al., 2006) with the alignment input format as CLUSAL $\mathrm{W}$ to obtain a 3D model for the protein. This model was viewed using the visualization software UCSF chimera (http://www.cgl.ucsf.edu/chimera) (Pettersen et al., 2004).

\section{Validation of model}

The protein model created need to be evaluated for quality. Hence the model was further checked with QMEAN, ANOLEA and GROMOS. QMEAN is a composite scoring function for both the estimation of the global quality of the entire model as well as for the local per-residue analysis of different regions within a model (Benkert, 2008). The reliability of the model ranges from $0-1$. The atomic empirical mean force potential ANOLEA (Melo and Feytmans, 1998) is used to assess packing quality of the models. The program performs energy calculations on a protein chain, evaluating the "Non- Local Environment" (NLE) of each heavy atom in the molecule. GROMOS (Van Gunsteren et $a l .$, , 1996) is a general-purpose molecular 
dynamics computer simulation package for the study of biomolecular systems and can be applied to the analysis of conformations obtained by experiment or by computer simulation. The model was further checked by Ramachandran plot at VADAR (Willard et al., 2003). WHAT IF server (http://swift.cmbi.ru. $\mathrm{nl} /$ servers/html/index.html) was used to check the nomenclature of torsion angles (Name check), the normality of the local environment of amino acids (Coarse Packing Quality Control), Anomalous bond lengths, Planarity, Fine Packing Quality Control, distribution of omega angles, Proline puckering and Anomalous bond angles.

\section{Solvent accessible regions}

The most biologically interesting residues are often exposed, as these are able to interact with the environment. So we looked in to the structure to predict the solvent accessible regions of the protein. The Solvent accessible prediction of OMP W of E. tarda was done using NetSurfP. (Petersen et al., 2009)

\section{Prediction of Antigenic Peptides}

Prediction of antigenic peptides was done using the EMBOSS tool 'Antigenic'. Antigenic predicts potentially antigenic regions of a protein sequence, using the method of Kolaskar and Tongaonkar (Rice et al., 2000). Analysis of data from experimentally determined antigenic sites on proteins has revealed that the hydrophobic residues Cys, Leu and Val, if they occur on the surface of a protein, are more likely to be a part of antigenic sites.

Cytotoxic T lymphocyte (CTL) epitopes in OMP W of E. tarda was identified by NetCTL 1.2 server. Computational tools involved in the prediction of subcellular localization illustrates where the protein resides in the cell. So if the protein is present in the outer membrane, there is more possibility that it can be highlighted as a potential drug target. The program PSORTb V.3.0 (http://www.psort. org/psortb/index.html) was used for sub cellular localization prediction (Gardy et al., 2005). Conserved domains of OMPs, which could be defined as part of protein sequence and structure that can evolve, function, and exist independent of the rest of the protein chain were identified using NCBI web interface 'CD search' (http://www.ncbi.nlm. nih.gov/Structure/cdd/wrpsb.cgi). Protein motifs, which are, short segments of protein three-dimensional structure or amino acid sequence that were found in a large number of different proteins were identified by 'motif search' of Genome Net Database Resources (http://www.genome.jp/tools/motif/).

Biologically significant protein patterns were determined using PROSCAN ((http://npsapbil.ibcp.fr/). PROSCAN help scan a sequence against the PROSITE database using its algorithm to find biologically relevant sites and signatures.

A protein if virulent has the property of adhesion. The software SEAPATH was used to determine the adhesive properties of OMP $\mathrm{W}$ of E. tarda. The programme works on Linux operating system and shows whether the protein is an adhesin, non adhesin or is in the twilight zone. Artificial neural networks (ANN) were used to develop SEAPATH, which predicts the probability of a protein being an adhesin (Pad) based on 105 compositional properties of a sequence. SEAPATH draws upon the base algorithm SPAAN (a software program for prediction of adhesins and adhesin-like proteins using neural networks), which had optimal sensitivity of $89 \%$ and specificity of $100 \%$ and could identify $97.4 \%$ of adhesins from a wide range of bacterial pathogens causing a broad range of diseases in humans and other hosts. 


\section{Results and Discussion}

OMP W of E. tarda is a 214 amino acid protein. The sequential diagram for homology modeling is depicted in Figure 1. Amino acid sequence of $E$. tarda OMP W (D0ZH93) is shown in Figure 2. NCBI Protein BLAST of E. tarda OMP W against $\mathrm{PDB}$ data base revealed that 2F1T_A; the OMP W of Escherichia Coli exhibited $61 \%$ identity with the protein, and hence was selected as the template for homology modeling. It is well established that proteins sharing more than $50 \%$ sequence homology adopt the same fold (Chothia and Lesk, 1986).

Proteins homologous over a length of at least 80 residues with at least $30 \%$ identical residues are predicted to share more than $70 \%$ secondary structure identity (Sander and Schneider, 1991); two or more proteins with $30 \%$ sequence identity differ in their threedimensional core structure by less than $1.5 \mathrm{~A}^{\circ}$.

Taking all these facts into consideration homology modelling could be a suitable method to obtain the 3D structure. The target (D0ZH93) template (2F1T_A) sequence alignment was done using CLUSTAL W and the resultant alignment file is shown in Figure 3 . The 3D structure of outer membrane protein of E. tarda obtained by homology modeling is shown in Figure 4A and 4B. Figure 4A reveals the central porous region enclosed by the transmembrane strands. In Figure 4B, the transmembrane strands, folding into antiparallel $\beta$-barrels could be seen.

\section{Validation of the model}

The QMEAN4 score is a composite score consisting of a linear combination of 4 statistical potential terms (estimated model reliability between 0-1). The pseudo-energies of the contributing terms are given below together with their Z-scores with respect to scores obtained for high-resolution experimental structures of similar size solved by X-ray crystallography. The QMEAN4 global scores of E. tarda OMP W is shown in Table 1 and the graphical representation is shown in Figure 5. The atomic empirical mean force potential ANOLEA was used to assess packing quality of the models. The graphical representation of packing quality of residues in the model is shown in Figure 6. Graphical representation of the analysis of conformations by GROMOS is shown in Figure 7.

In Figure 6 and 7, the $\mathrm{Y}$-axis of the plot represents the energy for each amino acid of the protein chain. Negative energy values (in green) represent favorable energy environment whereas positive values (in red) represent unfavorable energy environment for a given amino acid. The Ramachandran plot visualizes energetically allowed regions for backbone dihedral angles $\psi$ against $\varphi$ of amino acid residues in protein structure. The Ramachandran plot developed for the OMP W of E. tarda is shown in Figure 8.

\section{Nomenclature of torsion angles (Name check)}

No errors were detected in valine, threonine, isoleucine, leucine, arginine nomenclature. Again No errors were detected in tyrosine torsion angle, phenylalanine torsion angle, aspartic acid torsion angle, glutamic acid torsion angle and phosphate group naming conventions. In the atom names for nonhydrogen atoms no errors were detected.

\section{Normality of the local environment of amino acids (Coarse Packing Quality Control)}

The packing quality control per amino acid Average was -0.598 which is considered within the permitted limit. 
Table.1 QMEAN4 global scores

\begin{tabular}{|l|l|l|}
\hline Scoring function term & Raw score & Z-score \\
\hline C_beta interaction energy & 31.15 & -4.57 \\
\hline All-atom pairwise energy & -684.68 & -3.43 \\
\hline Solvation energy & -0.26 & -2.52 \\
\hline Torsion angle energy & -22.53 & -2.16 \\
\hline QMEAN4 score & 0.494 & -3.84 \\
\hline
\end{tabular}

Table.2 Antigenic peptides of E. tarda OMP W

\begin{tabular}{|l|c|c|c|l|}
\hline Score & Sequence length & Residue position & Max score position & Sequence \\
\hline 1.255 & 37 & $5-41$ & 9 & $\begin{array}{l}\text { KCSVALCLAAVLAPAAASAHQAGDVIV } \\
\text { RAGAATVRPT }\end{array}$ \\
\hline $\mathbf{1 . 1 4 1}$ & 11 & $119-129$ & 123 & RPYLGVGVNYT \\
\hline $\mathbf{1 . 1 2 5}$ & 34 & $75-108$ & 98 & $\begin{array}{l}\text { IELLAATPFRHKVSLGALGNIATVHQLPP } \\
\text { TLMAQ }\end{array}$ \\
\hline $\mathbf{1 . 0 8 7}$ & 7 & $142-148$ & 145 & SLGLHDL \\
\hline $\mathbf{1 . 0 8 2}$ & 9 & $45-53$ & 50 & DNVLGLGEF \\
\hline $\mathbf{1 . 0 7 6}$ & 7 & $173-179$ & 178 & NASVWYI \\
\hline 1.075 & 10 & $156-165$ & 159 & VAGQAGLDYM \\
\hline $\mathbf{1 . 0 3 2}$ & 6 & $203-208$ & 206 & PWVFMF \\
\hline
\end{tabular}

Table.3 Peptide sequence with cytotoxic T lymphocyte in E. tarda OMP W

\begin{tabular}{|l|}
\hline Sequence initial position \\
\hline 42 \\
\hline 69 \\
\hline 113 \\
\hline 128 \\
\hline 156 \\
\hline 170 \\
\hline 198 \\
\hline 204 \\
\hline
\end{tabular}

\begin{tabular}{|l|}
\hline Peptide sequence \\
\hline TSSDNVLGL \\
\hline ATDNIGIEL \\
\hline RAEDKLRPY \\
\hline YTTFFNNSF \\
\hline VAGQAGLDY \\
\hline WMINASVWY \\
\hline NTNINPWVF \\
\hline WVFMFGAGY \\
\hline
\end{tabular}

Fig.1 Sequential diagram for homology modeling

Target protein sequence

NCBI Protein BLAST choosing PDB as data base

Obtaining structurally similar template protein sequence

$\downarrow$

Target template MSA using CLUSTAL W

Alignment files as input to SWISS MODEL server

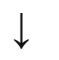

Visualization of structure 
Fig.2 Amino acid sequence of D0ZH93

\section{MMMKKCSVALCLAAVLAPAAASAHQAGDVIVRAGAATVRPTTSSDNVLGLGEFSVDNNTQLGLTFGYMATDNI GIELLAATPFRHKVSLGALGNIATVHQLPPT LMAQWYFGRAEDKLRPYLGVGVNYTTFFNNSFDQNAT SLGLHDLK ATDSWGVAGQAGLDYM VSENWMINASWWYINIDT KVKFRDSADNQHSINT NINPWVFMFGAGYRF}

Fig.3 Target (E. tarda OMP) -Template (E. coli OMP) alignment
E. tarda
E. coli
E. tarda
E. coli
E. tarda
E.coli
E. tarda
E. coli

MMVKCSVALCLA_AVLAPAAASAHQAGDVIVRAGAATVRPTTSSDNVLG-LGEFSVDNNT HEAGEFFMRAGSATVRPTEGAGGTLGSLGGFSVTNNT

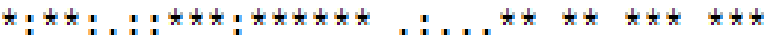

QLGLTFGYMATDNIGIELLAATPFRHKVSLGALGNIATVHQLPPTLMAQWYFGRAEDKLR QLGLTFTYMATDNIGVELLAATPFRHKIGTRATGDIATVHHLPPTLMAQWYFGDASSKFR

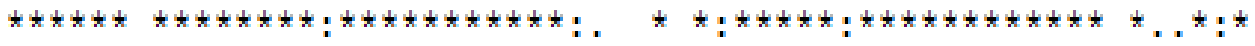

PYLGVGVNYTTFFNNSFDQNATSLGLHDLKATDSWGVAGQAGLDYMVSENWMTNASVWYI PYVGAGINYTTFFDNGFNDHGKEAGLSDLSLKDSWGA.AGQVGVDYLINRDWLVNMSVWYM

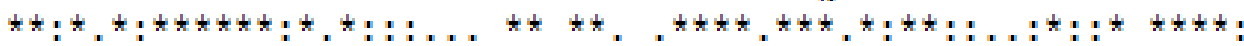
NIDTKVKFRDSADNQHSINTNINPWVFMFGAGYRF-----DIDTTANYKLGGAQQHDS-VRLDPWVFMFSAGYRFHHHHHH

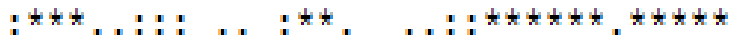

Fig.4A E. tarda OMP W revealing the centre porous region

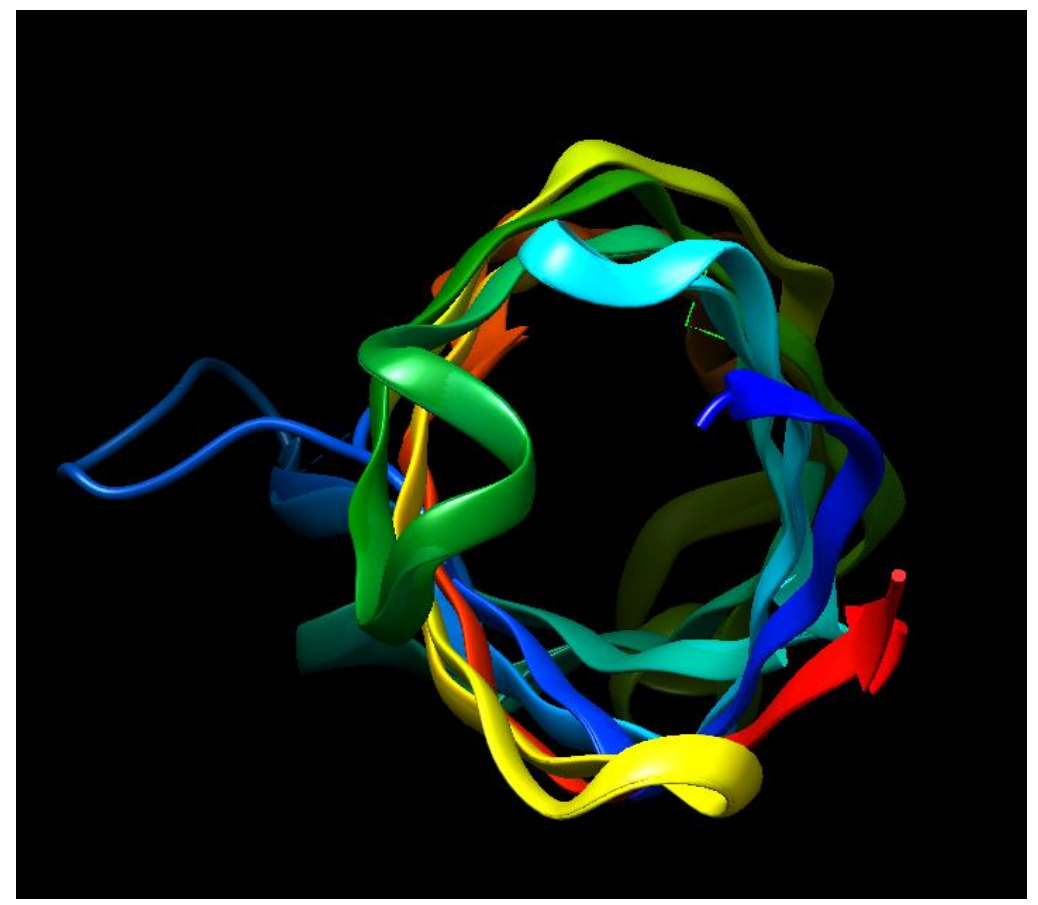


Fig.4B 3D Structure of E. tarda OMP W depicting the anti-parallel beta strands

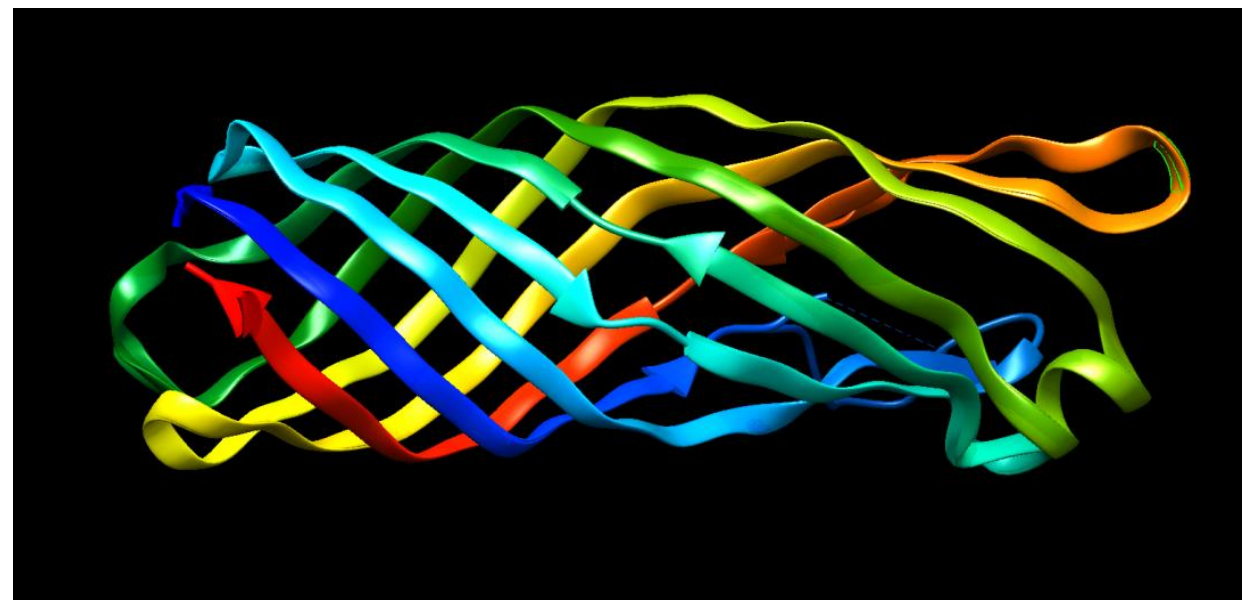

Fig.5 Graphical representation Q means score of each residue of E. tarda OMP W

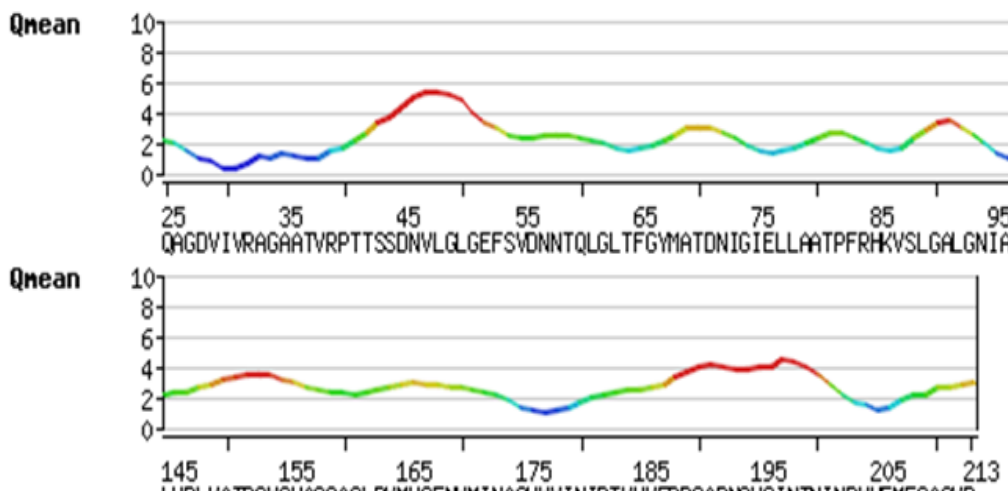

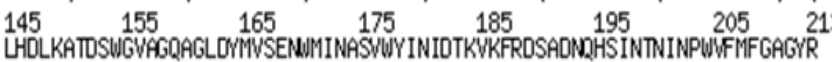

Sequence colored by local quality:

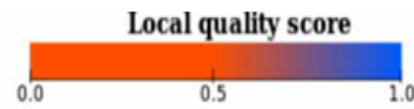

Fig.6 Packing quality of the homology based structure of E. tarda OMP W

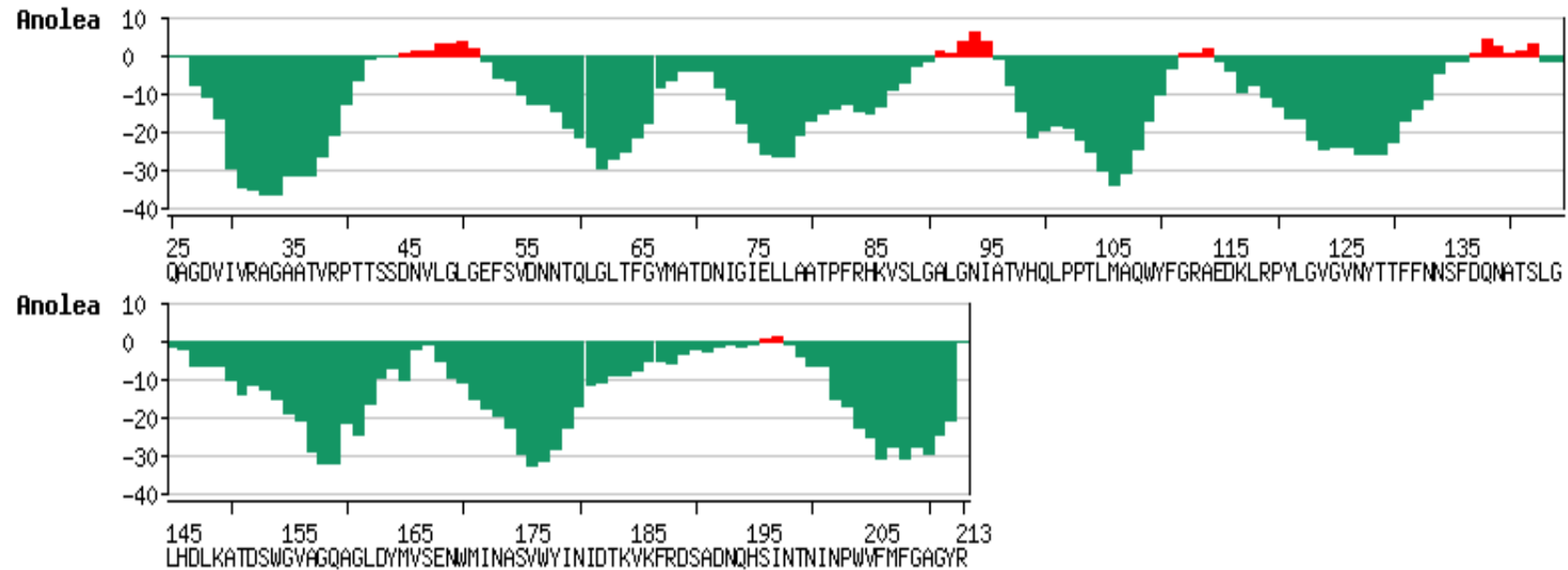


Fig.7 GROMOS results

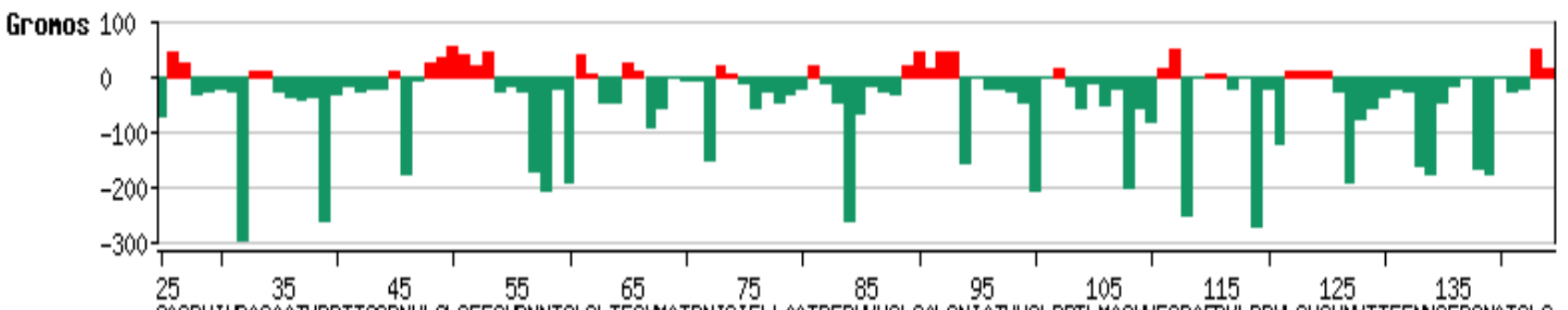

Gronos 100

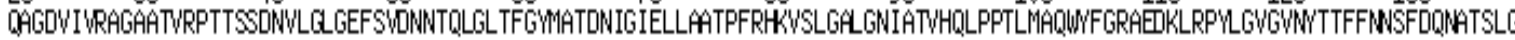

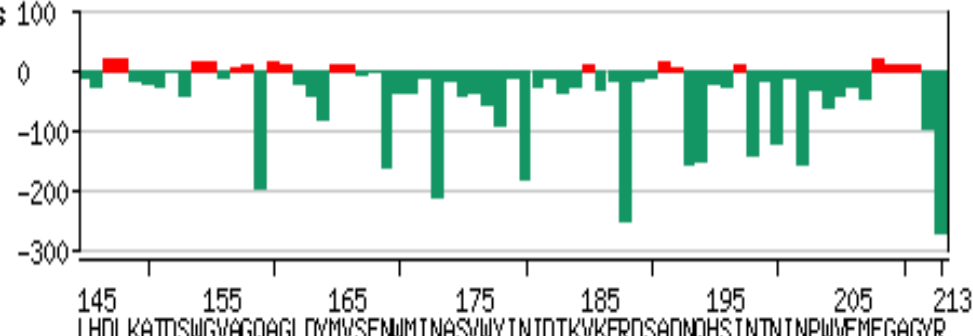

Fig.8 Ramachandran Plot of E. tarda OMP W

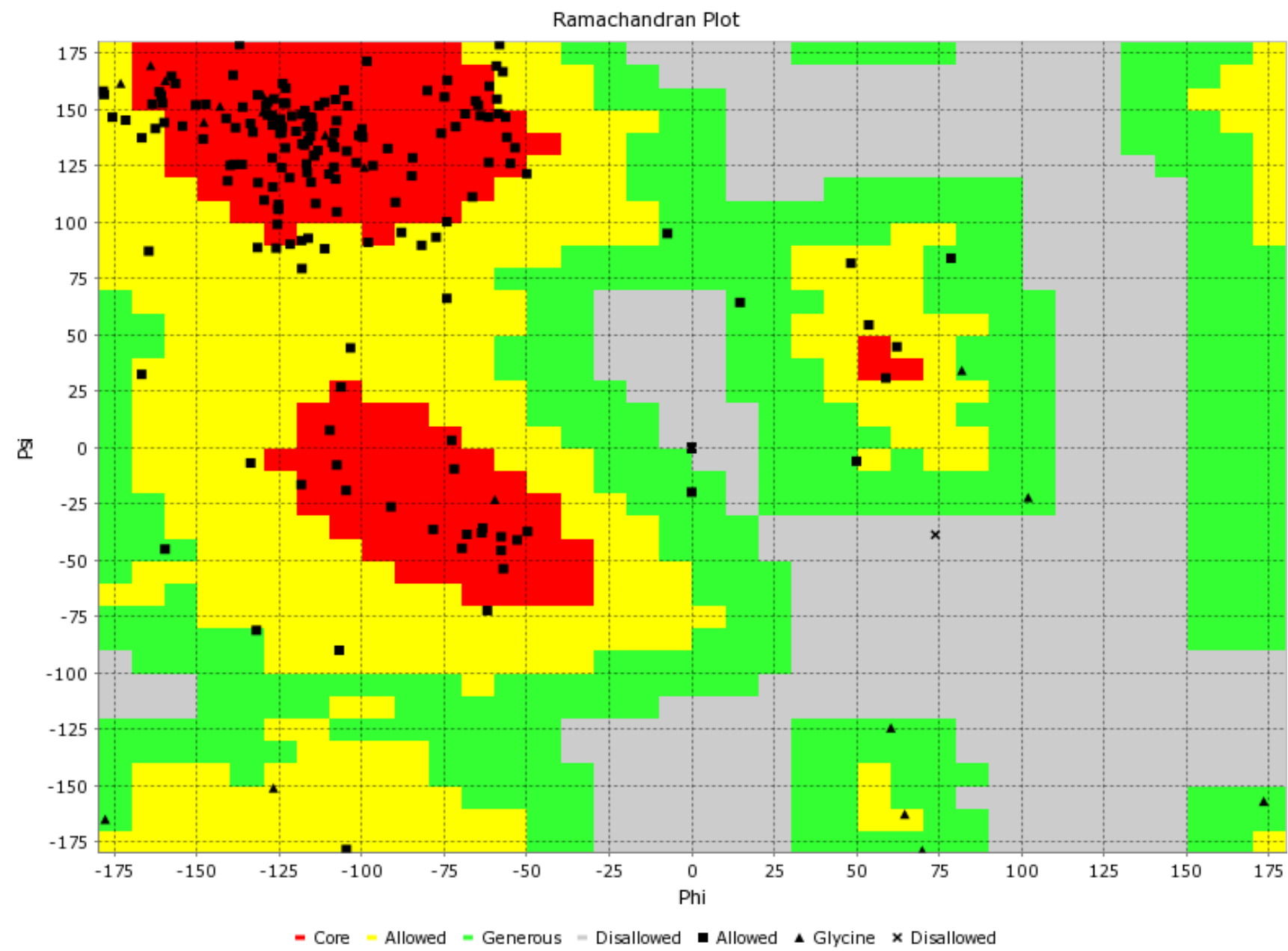




\section{Anomalous bond lengths}

The standard values and sigmas for the bond lengths of amino acid residues have been taken from Engh and Huber (1991). The bond lengths which deviated more than 4 sigma from standard bond lengths were considered unusual. In this model the bond lengths were found to deviate less than normal from the mean standard bond lengths.

The RMS Z-score given below is expected to be around 1.0 for a normally restrained data set. But in this model the RMS Z-score for bond lengths is 0.654 and the RMS-deviation in bond distances is 0.013 indicating that toostrong restraints might have been used in the refinement.

\section{Planarity validation results}

In the structure all of the atoms that are connected to planar aromatic rings in side chains of amino-acid residues are in the plane within expected RMS deviations. But the side chains of the residues ASP (137th position) and GLN (25th position) was found to deviate from planarity by more than 4.0 times the expected value. For an amino acid residue that has a side chain with a planar group, the RMS deviation of the atoms to a least squares plane was determined. The RMS value of ASP and GLN deviates 7.34 and 5.74 times standard deviation from the expected value.

\section{Fine packing quality control}

Structural validation for fine packing quality control of the Homology based model of $E$. tarda OMP showed that the average $\mathrm{Z}$-score for all contacts (BB-BB, BB-SC, SC-BB and $\mathrm{SC}-\mathrm{SC}$ ) is 0.03 , which confirms the structure is good. Here $\mathrm{BB}$ and $\mathrm{SC}$ is the minimal distance between the heavy atoms of the protein backbone and side chains of the two residues respectively.

\section{Distribution of omega angles}

The omega angles for trans-peptide bonds in a structure are expected to give a Gaussian distribution with the average around +178 degrees, and a standard deviation around 5.5. In the current structure the omega average and standard deviation values are 178.208 and 6.322 respectively which agrees with this expectation.

\section{Proline puckering}

Puckering amplitudes and puckering phases for all Proline residues are within normal ranges.

\section{Anomalous bond angles}

Except for the residues ASP (116), MET (165), VAL (185) and HIS (195) which has strange bond angles of 108.46, 92.08, 99.74 and 109.23 all other bond angles fall within the standard value described in Engh and Huber (1991). The RMS Z-score for bond angles was 1.053 and the RMS-deviation in bond angles was 1.928 .

\section{Solvent Accessible Regions}

The solvent accessible regions of E. tarda as calculated by NetSurfP predicted 101 exposed residues in the peptide chain.

\section{Prediction of antigenic peptides}

The antigenic peptides as predicted by EMBOSS 'antigenic' shows that eight peptide sequences of the OMP are antigenic. The antigenic peptides and the score are shown in Table 2. Cytotoxic T lymphocyte (CTL) epitopes in OMP W of E. tarda identified by NetCTL 1.2 server is presented in Table 3.

The subcellular localization prediction by PSORTb V.3.0 confirmed that OMP W of $E$. 
tarda is localized in the outer membrane of the bacteria. The CD search conducted to find the conserved domains in E. tarda OMP W showed that Surface antigen 2 super family domain is present. An Enterobacterial virulence outer membrane protein signature 2 was found in between residue 206 and 214 with the peptide sequence FMFGAGYRF by the Motif search. The different patterns associated with E. tarda OMP are Nglycosylation site, cAMP- and cGMPdependent protein kinase phosphorylation site, Protein kinase $\mathrm{C}$ phosphorylation site, Casein kinase II phosphorylation site and Nmyristoylation site as obtained from PROSCAN.

SEAPATH is linux based software, which classifies the proteins as adhesins or non adhesins based on the probability of adhesive (Pad) value. A protein with a Pad value $\geq 0.7$ is an adhesin and could be considered as virulent. If the Pad value is $\leq 0.4$, then it is a non adhesin. A value between 0.4 and 0.7 suggests that the protein is in the twilight zone i.e it could be an adhesin or a nonadhesin depending upon the proximity of the Pad value to the upper or lower limit. SEAPATH analysis confirmed E. tarda OMP $\mathrm{W}$ as an adhesin.

\section{References}

Arnold, K., Bordoli, L., Kopp, J. and Schwede, T., 2006. The SWISSMODEL workspace: a web-based environment for protein structure homology modelling. Bioinfo., 22(2), pp.195-201.

Benkert, P., Tosatto, S.C. and Schomburg, D., 2008. QMEAN: A comprehensive scoring function for model quality assessment. Proteins: Struct. Funct. Bioinfo., 71(1), pp.261-277.

Chothia, C. and Lesk, A.M., 1986. The relation between the divergence of sequence and structure in proteins. The EMBO J., 5(4), pp.823-826.

Clarridge, J.E., Musher, D.M., Fainstein, V. and Wallace, R.J., 1980. Extra intestinal human infection caused by Edwardsiella tarda. J. of Clin. Microbiol., 11(5), pp. 511-514.

Czirják, G.Á., Köbölkuti, L.B., Cătoi, C., Tenk, M., Szakács, A., Cadar, D., Ungvári, A. and Uricaru, A., 2008. Multiple subcutaneous abcesses caused by Edwardsiella tarda in captive grass snake (Natrix natrix). J. Vet. Res., 68, pp.175-182.

Dubey, S., Avadhani, K., Mutalik, S., Sivadasan, S.M., Maiti, B., Paul, J., Girisha, S.K., Venugopal, M.N., Mutoloki, S., Evensen, $\varnothing$. and Karunasagar, I., 2016. Aeromonas hydrophila OmpW PLGA nanoparticle oral vaccine shows a dose-dependent protective immunity in rohu (Labeo rohita). Vaccines, 4(2), p.21.

Engh, R.A. and Huber, R., 1991. Accurate bond and angle parameters for X-ray protein structure refinement. Acta Crystallographica Section A: Foundations of Crystallography, 47(4), pp. 392-400.

Gardy, J.L., Laird, M.R., Chen, F., Rey, S., Walsh, C.J., Ester, M. and Brinkman, F.S., 2005. PSORTb v.2.0: expanded prediction of bacterial protein subcellular localization and insights gained from comparative proteome analysis. Bioinfo., 21: 617-623

Hong, H., Patel, D.R., Tamm, L.K. and van den Berg, B., 2006. The outer membrane protein $\mathrm{OmpW}$ forms an eight-stranded $\beta$-barrel with a hydrophobic channel. J. Biol. Chem., 281(11), pp.7568-7577.

Kusuda, R. and Kawai, K., 1998. Bacterial diseases of cultured marine fish in Japan. Fish Pathol., 33(4), pp.221-227. 
Lüthy, R., Bowie, J.U. and Eisenberg, D., 1992. Assessment of protein models with three-dimensional profiles. Nature, 356(6364), p.83.

Maiti, B., Raghunath, P. and Karunasagar, I., 2009. Cloning and expression of an outer membrane protein $\mathrm{OmpW}$ of Aeromonas hydrophila and study of its distribution in Aeromonas spp. J. App. Microbiol., 107(4), pp.1157-1167.

Manchanda, V., Singh, N.P., Eideh, H.K., Shamweel, A. and Thukral, S.S., 2006. Liver abscess caused by Edwardsiella tarda biogroup 1 and identification of its epidemiological triad by ribotyping. Ind. J. Med. Microbiol., 24(2), p.135.

Melo, F. and Feytmans, E., 1998. Assessing protein structures with a non-local atomic interaction energy1. J. of Mol. Biol., 277(5), pp.1141-1152.

Nandi, B., Nandy, R.K., Sarkar, A. and Ghose, A.C., 2005. Structural features, properties and regulation of the outermembrane protein $\mathrm{W}(\mathrm{OmpW})$ of Vibrio cholerae. Microbiol., 151(9), pp.2975-2986.

Petersen, B., Petersen, T.N., Andersen, P., Nielsen, M. and Lundegaard, C., 2009. A generic method for assignment of reliability scores applied to solvent accessibility predictions. BMC Struct. Biol., 9(1), p.51.

Pettersen, E.F., Goddard, T.D., Huang, C.C., Couch, G.S., Greenblatt, D.M., Meng, E.C. and Ferrin, T.E., 2004. UCSF Chimera-a visualization system for exploratory research and analysis. J. of Computat. Chem.. 25(13), pp.16051612.

Revol, B., 1995. Crocodile farming and conservation, the example of Zimbabwe. Biodiversity and Conservation, 4(3), pp.299-305.

Rice, P., Longden, I. and Bleasby, A., 2000. EMBOSS: the European molecular biology open software suite.
Sander, C. and Schneider, R., 1991. Database of homology- derived protein structures and the structural meaning of sequence alignment. Proteins: Struct. Funct. Bioinfo., 9(1), pp.56-68.

Sechter, I., Shmilovitz, M., Altmann, G., Seligmann, R., Kretzer, B., Braunstein, I. and Gerichter, C.B., 1983. Edwardsiella tarda isolated in Israel between 1961 and 1980. J. Clin. Microbiol., 17(4), pp.669-671.

Sharma, V.K., Kaura, Y.K. and Singh, I.P., 1974. Frogs as carriers of Salmonella and Edwardsiella. Antonie Van Leeuwenhoek, 40(1), pp.171-175.

Spencer, J.D., Hastings, M.C., Rye, A.K., English, B.K. and Ault, B.H., 2008. Gastroenteritis caused by Edwardsiella tarda in a pediatric renal transplant recipient. Pediatric transplantation, 12(2), pp.238-241.

Stock, I. and Wiedemann, B., 2001. Natural Antibiotic Susceptibilities of Edwardsiella tarda, E. ictaluri, and E. hoshinae. Antimicrobial agents and chemotherapy, 45(8), pp.2245-2255.

Thornton, S.M., Nolan, S. and Gulland, F.M., 1998. Bacterial isolates from California sea lions (Zalophus californianus), harbor seals (Phoca vitulina), and northern elephant seals (Mirounga angustirostris) admitted to a rehabilitation center along the central California coast, 1994-1995. J. Zoo Wildlife Med., pp.171-176.

Van Gunsteren, W.F., Billeter, S.R., Eising, A.A., Hünenberger, P.H., Krüger, P.K.H.C., Mark, A.E., Scott, W.R. and Tironi, I.G., 1996. Biomolecular simulation: the \{GROMOS96\} manual and user guide.

Welch, T.J., Evenhuis, J., White, D.G., McDermott, P.F., Harbottle, H., Miller, R.A., Griffin, M. and Wise, D., 2009. IncA/C plasmid-mediated florfenicol resistance in the catfish pathogen 
Edwardsiella ictaluri. Antimicrobial agents and chemotherapy, 53(2), pp.845-846.

Willard, L., Ranjan, A., Zhang, H., Monzavi, H., Boyko, R.F., Sykes, B.D. and Wishart, D.S., 2003. VADAR: a web server for quantitative evaluation of protein structure quality. Nucleic Acids Res., 31(13), pp.3316-3319.
Xu, C., Ren, H., Wang, S. and Peng, X., 2004. Proteomic analysis of salt-sensitive outer membrane proteins of Vibrio parahaemolyticus. Res. Microbiol., 155(10), pp.835-842.

Ye, S., Li, H., Qiao, G. and Li, Z., 2009. First case of Edwardsiella ictaluri infection in China farmed yellow catfish Pelteobagrus fulvidraco. Aquaculture, 292(1-2), pp.6-10.

\section{How to cite this article:}

Neema, M. and Karunasagar, I. 2018. In Silico Homology Modeling and Epitope Prediction of Outer Membrane Protein OMP W, A Potential Vaccine Candidate against Edwardsiella tarda. Int.J.Curr.Microbiol.App.Sci. 7(03): 2762-2773. doi: https://doi.org/10.20546/ijcmas.2018.703.319 